\title{
CONTEÚDOS E OBJETIVOS DA CRECHE À LUZ DA TEORIA HISTÓRICO-CULTURAL
}

José Ricardo Silva

Universidade Estadual Paulista - UNESP, Presidente Prudente, SP. E-mail: ricardo.unesp@hotmail.com.

\section{RESUMO}

A partir de nossa experiência enquanto formador de professores de creche constatamos o quanto as práticas pedagógicas desenvolvidas são realizadas no espontaneismo, ou seja, não há planejamento. Orientados pela teoria histórico-cultural, estamos convencidos de que os professores podem contribuir com o desenvolvimento humano desde a tenra idade. De caráter bibliográfico, este texto tem como objetivo discutir quais são os objetivos e os conteúdos requeridos para promoverem o desenvolvimento de bebês na creche. Os autores apontam que os conteúdos para bebês são operacionais e os professores irão propô-los de forma indireta. Para isso, os objetos e os brinquedos são essenciais. É papel do professor, então, planejar vivências, materiais, espaço e tempo de modo a promover o desenvolvimento dos bebês.

Palavras Chaves: Creche; bebês; professor; desenvolvimento; humanização.

\section{CONTENTS AND OBJECTIVES OF DAY CARE IN THE LIGHT OF HISTORICAL-CULTURAL THEORY}

\begin{abstract}
From our experience as teacher trainer of nursery school we verified how much the pedagogical practices developed are carried out in spontaneity, that is, there is no planning. Guided by historical-cultural theory, we are convinced that teachers can contribute to human development from an early age. Of bibliographical character, this text has as objective to discuss what are the objectives and the contents required to promote the development of infants in the nursery. The authors point out that the contents for babies are operational and teachers will propose them in an indirect way. For this, objects and toys are essential. It is the role of the teacher, then, to plan experiences, materials, space and time in order to promote the development of babies.
\end{abstract}

Keywords: Nursery school; babies; teacher; development; Humanization. 


\section{INTRODUÇÃO}

A temática aqui abordada surge a partir de nossas experiências com formação de professores de creche. Constatamos que as concepções e as práticas relatadas pelos docentes ilustram que organizam, decidem e colocam em prática a rotina, dirigem o tempo, organizam o espaço e disponibilizam objetos e brinquedos tomando como referência a experiência de anos anteriores e com os colegas de trabalho. Além disso, confessam que decidem no dia o que irão propor aos bebês alegando má formação inicial e falta de tempo para o preparo da rotina.

$\mathrm{Na}$ mesma direção, outros pesquisadores vêm apontando esta problemática no atendimento de bebês nas instituições educacionais brasileiras. Dagnoni (2012) aponta para a predominância de saberes experienciais, um saber específico do cotidiano da creche, que se constitui de forma singular durante as práticas, agregando as experiências profissionais e pessoais das professoras numa cultura própria na instituição. Silva (2008), constatou em pesquisa de campo realizada em instituições de educação infantil que o trabalho docente ainda está mais voltado para questões assistenciais do que educativas.

Em contextos assim, bebês e crianças ficam submetidas às determinações dos adultos que atuam profissionalmente nas instituições. Devido à relação de dependência com os adultos, os bebês e crianças ouvem, veem, sentem e se locomovem a partir da organização espacial e temporal estabelecida. Ainda, por vezes, vivem situações de poucos estímulos, escassez de materiais para explorar e com tempo e espaços limitados e reduzidos. Por esta razão, as manifestações de interesse dos bebês e das crianças não são consideradas pelos professores. Tais práticas refletem a concepção que estes profissionais possuem acerca dos objetivos e os conteúdos inerentes a esta etapa da Educação Básica.

Estas atitudes podem ser fruto da não compreensão por parte dos profissionais de que os bebês e as crianças se desenvolvem quando estabelecem uma relação ativa com o entorno. Para isso, faz-se necessário conhecer as especificidades da infância para sinalizar os objetos e os conteúdos próprios desta etapa da educação.

Neste sentido, queremos pensar a prática pedagógica na Educação Infantil de modo a superar o assistencialismo e, ao mesmo tempo não incorporar a antecipação de conteúdos escolares. Assim, o objetivo deste texto é discutir quais são os objetivos e os conteúdos requeridos para promoverem o desenvolvimento de bebês na creche.

\section{METODOLOGIA}

De delineamento qualitativo, este trabalho caracteriza-se como pesquisa bibliográfica, pois busca em produção já existente, contornos que sustentem a discussão necessária para a elucidação do problema elencado (SEVERINO, 1990). Este texto ancora-se na teoria históricocultural, portanto, consideramos alguns de seus principais autores - Vigotski (2008), Mukhina (1996), Martins (2009, 2013) e Saviani (2011).

\section{RESULTADOS}

Inicialmente, é fundamental compreender que existe um ato educativo a ser desenvolvido pelo professor preocupado com o desenvolvimento infantil. Para isso, ele precisa, intencionalmente, proporcionar e intervir nas vivências para que elas se tornem experiências que possibilitem o desenvolvimento (SAVIANI, 2011). Pensar em ato educativo é, neste trabalho, entender que o professor é responsável por planejar, organizar, sistematizar e orientar determinado conhecimento com o intuito de contribuir com o desenvolvimento daqueles que atende, as crianças. Nos apoiamos em Saviani quando este define o ato educativo como

[...] o ato de produzir, direta e intencionalmente, em cada indivíduo singular, a humanidade que é produzida histórica e coletivamente pelo 
conjunto dos homens. Assim, o objeto da educação diz respeito, de um lado, à identificação dos elementos culturais que precisam ser assimilados pelos indivíduos da espécie humana para que eles se tornem humanos e, de outro lado e concomitantemente, à descoberta das formas mais adequadas para atingir esse objetivo. (SAVIANI, 2011, p. 13)

Partindo desta clássica citação de Saviani, somos levados a esclarecer outras questões que se colocam: quais elementos culturais devem ser entendidos como conteúdo de ensino para a Educação Infantil?

Neste momento nos apoiamos em Martins (2009, p. 94) quando esta os define como "(...) os conhecimentos mais elaborados e representativos das máximas conquistas dos homens, ou seja, componentes do acervo científico, tecnológico, ético, estético etc. convertidos em saberes escolares. " Na mesma direção, complementa Saviani, dizendo que os conteúdos de ensino "[...] diz respeito ao conhecimento elaborado e não ao conhecimento espontâneo; ao saber sistematizado e não ao saber fragmentado; à cultura erudita e não à cultura popular (SAVIANI, 2011, p. 14)."

Martins (2009), direcionando suas preocupações sobre o trato pedagógico com bebês e crianças, defende que estes conteúdos não devem encerrar em si os objetivos escolares, caso contrário, seriam vazios de significados e não passariam de meras distrações/ocupações. De certo os conteúdos para a escola infantil são aqueles que ampliam as possibilidades de controle do ser humano sobre si mesmos e sobre o mundo, ou seja, os conteúdos específicos da Educação Infantil são aqueles que desenvolvem as funções psíquicas superiores. Esta relação fica ainda mais clara ao levarmos em consideração que, ao nascer, o bebê apresenta Funções Psíquicas Elementares e, socialmente poderá desenvolver Funções Psíquicas Superiores que facilitarão cada vez mais sua relação com o mundo externo.

Para a autora, no trato pedagógico com o bebê, os conteúdos de ensino são entendidos como conteúdo de formação operacional devido a sua situação social de desenvolvimento como ser operante. Esta especificidade do bebê, o reconhecimento dos indicativos psicológicos e os conteúdos a serem ensinados, devem estar sob o domínio do professor pois, subjazem às suas propostas como saberes interdisciplinares pois não são transmitidos em seu conteúdo conceitual produzindo uma aprendizagem indireta na relação estabelecida. Como exemplo de conteúdos com esta natureza, destacamos a acuidade perceptiva e sensorial, domínios psicofísicos e sociais e a destreza psicomotora. Para as crianças, a autora defende conteúdos de formação teórica desde que dentro de uma relação de proporcionalidade indireta, isto é, na relação bebê/professor há a predominância de conteúdos de formação operacional sobre conteúdos de formação teórica ao passo que, com o decorrer do tempo haverá a prevalência de conteúdos de formação teórica sobre conteúdos de formação operacional.

Esta premissa reforça ainda mais a necessidade da comunicação verbal entre professor e bebê, já que é deste modo que os objetos e as ações humanas ganham denominação e significado. Já não é mais necessário que os bebês criem sons e palavras a partir das experiências práticas para designar seus atos, também, não é mais necessário que criem objetos e os nomeiem. A cultura humana, em sua historicidade, já avançou estas condições. Portanto, não podemos mais permitir que o trabalho realizado com os bebês seja entendido como momentos meramente livres sem qualquer tipo de orientação ou significação social. Esta é uma premissa básica quando objetivamos o máximo desenvolvimento dos bebês quando inseridos nas creches. Mas como trabalhar com conteúdo de ensino com bebês quando estes ainda não leem, não escrevem, não falam com o professor ou com seus pares? 


\section{DISCUSSÃO}

Saviani (2011) têm-se preocupado, não exclusivamente sobre práticas pedagógicas com bebês, com a importância da educação como um ato que produz o não material. Na busca para tentarmos responder nossos questionamentos, nossa compreensão da obra do autor nos leva a compreender que, para ele, o produto da prática pedagógica com bebês, o conhecimento humano acumulado, não se separa do produtor durante a atividade mediada pelo professor, no caso o bebê no ato de sua vivência. "Trata-se aqui da produção de ideias, conceitos, valores, símbolos, hábitos, atitudes, habilidades" (SAVIANI, 2011, p. 12). Caracterizando, assim, a educação e, sobretudo o trabalho pedagógico com os bebês como educação não-material, relação que gera, para além de coisas, mas a forma pela qual ele apreende o mundo em que vive e alimenta o seu espírito.

Quando nós falamos que a educação é uma produção não material, isso significa que a atividade que a constitui se dirige a resultados que não são materiais, diferentemente da produção material, que é uma ação que se desenvolve e se dirige a resultados materiais (SAVIANI, 2011, p. 90).

Esta concepção não pode ir ao encontro daquelas que esperam um produto sempre palpável ou apresentável aos pais ou à coordenação da escola, sob forma de resultado final como aquelas encontradas e produzidas por crianças maiores, por exemplo, na pré-escola. À luz destes teóricos, estamos entendendo que o ato educativo com os bebês não pode ser pautado sobre a produção material, mas a partir do planejamento, organização e mediação do professor. Que estes momentos sejam de experimentação, de vivência significativa, de exploração, de investigação e descobertas, de pesquisas realizadas pelo próprio bebê através de todos os seus órgãos dos sentidos e seu próprio corpo para que ele adquira hábitos e atitudes que sua herança biológica não oferece, ou seja, hábitos e atitudes humanas.

Entretanto, mesmo que tenhamos claro os conteúdos que se referem a esta etapa da educação, faz-se, consequentemente, saber dosar este conhecimento de modo a possibilitar aos bebês o apoderamento destes saberes que o humanizarão. Para Mukhina (1996) quanto menor é a criança, mais elementares e simples serão os conhecimentos que ela poderá assimilar. Para prosseguirmos com esta discussão, outras questões precisam ser respondidas: Quais são os objetivos da Educação Infantil? Qual a forma mais adequada para atingir este objetivo?

Fica claro pensarmos que o conteúdo que se destina ao bebê precisa receber, por parte do professor, determinada adaptação. O conhecimento mais elaborado para este destinatário, aparentemente, compõe um conjunto de saberes simples, no entanto, não podemos perder de vista suas especificidades. Destarte, serão estes conteúdos, mediados pelo professor, que se relacionam com o seu nível de desenvolvimento. Sob estas indicações, encontram-se, como exigência primeira no planejamento de ensino a forma, os conteúdos de ensino e destinatário. "Como tal, nenhum desses elementos, esvaziados das conexões que os vinculam podem, de fato, orientar o trabalho pedagógico (MARTINS, 2013, p. 297)."

Obviamente, que não caberá ao professor de bebês ensinar, mas emprestar sua consciência a ele de modo a lança-lo em desenvolvimento. Será por esta via que o bebê irá superar sua condição elementar em direção à atividade humana consciente. Ao entender esta situação e compreender sua importância, Vigotski (2008) acredita que o professor pode agir eficazmente com e sobre o bebê objetivando o seu desenvolvimento psicológico e social ao trabalhar sob a luz da zona de desenvolvimento proximal.

Vigotski (2008) destaca que por meio de suas vivências e experimentações o ser humano consegue estabelecer e manter um nível de desenvolvimento psíquico, isto significa que o conhecimento elaborado encontrado nela, o qual domina e conhece mentalmente, corresponde ao seu nível de desenvolvimento real. Mas há também momentos de resoluções de problemas ou 
desafios que a criança só poderá superar com o auxílio de outra pessoa mais preparada (um adulto responsável, um professor ou até mesmo outra criança), denominado como nível de desenvolvimento potencial. Visando este nível que deve incidir a ação do professor.

Esta evolução do comportamento humano ocorre, precisamente, no momento em que se adquire independência de alguns comportamentos e, no entanto, ainda para outros mais complexos, continuam dependentes de intervenções alheias para sua objetivação. $O$ espaço entre estes dois pontos é denominado, por Vigotski (2008), como zona de desenvolvimento proximal. Em suas próprias palavras:

Ela é a distância entre o nível de desenvolvimento real, que se costuma determinar através da solução independente de problemas, e o nível de desenvolvimento potencial, determinado através da solução de problemas sob orientação de um adulto ou em colaboração com companheiros mais capazes. (VIGOTSKI, 2008, p. 97)

Ao entender esta situação, Vigotski (2008) acredita que o professor pode trabalhar sob a luz da zona de desenvolvimento proximal. Assim, a intervenção pedagógica do professor torna-se imprescindível. Quanto mais ricas as intervenções educativas dos professores, maiores serão as conquistas do bebê no mundo em que vive. O foco pedagógico, portanto, será o conhecimento a ser ampliado, a partir de conquistas adquiridas anteriormente em seu desenvolvimento.

Mas, para atuar sobre estes processos, reiteramos a necessidade de domínio do professor sobre os saberes que procuramos expor até este ponto. Por sua natureza, a prática pedagógica com bebês deve ser aliada a condições de estudos teóricos sobre o desenvolvimento humano. Este domínio irá possibilitar ao professor a capacidade de observar e captar as 'mensagens' emitidas pelos bebês (movimento, olhar, choro, sorriso) quando estes buscam comunicar suas necessidades e interesses.

O domínio do conhecimento [...] a ser transmitido e os conceitos que se pretende ensinar são ferramentas imprescindíveis para que o professor opere com e por meio delas de maneira prática, sintonizada à concreticidade e empiria do pensamento infantil, sem, contudo, se deixar aprisionar por elas (MARTINS, 2013, p. 295).

\section{CONCLUSÕES}

O bebê e a criança pequena precisam se apropriar da cultura e, para isso, faz-se necessário que, quando em âmbito institucional, o professor assuma o papel de mediador da cultura, ensineos a se apropriarem dos objetos, de si mesmos, da fala, das regras de convivência, de seus movimentos, da arte, das tecnologias, das ciências, enfim, que se aproprie da cultura humana.

É nesta direção que dizemos que cabe aos professores planejar, sistematizar, organizar momentos, espaços, objetos e tempo que garantam vivências suficientes para que os bebês se desenvolvam. Para isso, faz-se necessário considerar os conteúdos e as formas adequadas a este destinatário. Quando discutimos o trabalho docente com bebês, precisamos ter claro que a situação social de desenvolvimento deste destinatário requer do professor uma adaptação dos conteúdos humanos a seres disponíveis na creche. Neste momento se destacam as vivências práticas, plásticas e as lúdicas, tendo como suporte os objetos e os brinquedos. Não desaparece deste cenário a figura do professor que faz a mediação entre a cultura encarnada nestes objetos e brinquedos e os bebês. Para tanto, o professor utiliza da linguagem, senta próximo aos bebês, dialoga com o grupo ou individualmente, compreende que o bebê possui um tempo próprio e um modo específico de se relacionar com os objetos, com o ambiente e com seus pares.

Estes indicativos superam as problemáticas apontadas no início do texto. Há um trabalho a ser realizado pelos professores na creche. Estes profissionais não podem mais se furtarem de promover o desenvolvimento em questão. 


\section{REFERÊNCIAS}

DAGNONI A. P. R. Quais as fontes de saberes das professoras de bebês? Anais, 35a Reunião anual da Anped, Porto de Galinhas, 2012. Disponível em:

<http://35reuniao.anped.org.br/images/stories/trabalhos/GT07\%20Trabalhos/GT071910_int.pdf> Acesso em: 02 maio 2014.

MARTINS L. M. O ensino e o desenvolvimento da criança de zero a três anos. (In) ARCE, A.;

MARTINS, L. M. Ensinando aos pequenos: de zero a três anos. Campinas: Alínea, 2009.

. O desenvolvimento do psiquismo e a educação escolar: contribuições à luz da psicologia

histórico-cultural e da pedagogia histórico-crítica. Campinas, Autores Associados, 2013.

MUKHINA, V. Psicologia da idade pré-escolar. São Paulo: Martins Fontes, 1996.

SAVIANI, D. Pedagogia histórico-crítica: primeiras aproximações. 11.ed.rev. Campinas, SP:

Autores Associados, 2011.

SEVERINO A. J. Metodologia do trabalho científico. São Paulo, Cortez editora, 1990.

SILVA, J. C. Práticas Educativas: a relação entre cuidar e educar e a promoção do desenvolvimento infantil à luz da Psicologia Histórico-Cultural. Dissertação (Mestrado em Educação Escolar) Universidade Estadual Paulista, Faculdade de Ciências e Letras, Campus de Araraquara, 2008.

VIGOTSKI L. S. Formação social da mente, São Paulo, Martins Fontes, 2008. 